\title{
Lipid Levels in Acute Coronary Syndromes Admitted in Medical Intensive Care Unit in a Tertiary Care Hospital
}

\author{
Aparna Patange ${ }^{1}$, Sandeep Immadisetty², Harshal Vora ${ }^{3}$, Hetal Mankodia ${ }^{4}$ \\ ${ }^{1}$ Department of Medicine, KIMS, Karad, Maharashtra, India. ${ }^{2}$ Department of Medicine, KIMS, Karad, Maharashtra, \\ India. ${ }^{3}$ Department of Medicine, KIMS, Karad, Maharashtra, India. ${ }^{4}$ Department of Medicine, KIMS, Karad, \\ Maharashtra, India.
}

\section{ABSTRACT}

\section{BACKGROUND}

Coronary artery disease (CAD) is the leading cause of mortality in men and women. Acute coronary syndrome (ACS), is a major reason for hospitalisation in our country. Dyslipidemia has been identified as one of the most important modifiable risk factors for CAD. The aim of the study was to determine the prevalence and pattern of dyslipidaemia and its relation to other modifiable risk factors.

\section{METHODS}

100 cases were studied in a Krishna Institutes of Medical Sciences, Karad, over a period of 12 months from $1^{\text {st }}$ August 2015 to $31^{\text {st }}$ July 2016. This is a prospective observational study. All adults $>18$ years of age admitted for acute coronary syndrome were eligible for this study. The ACS group was studied as STEMI, NSTEMI, and Unstable Angina.

\section{RESULTS}

Majority of patients (33) was in the age group 51-60 years followed by 29 patients in the age group 61-70 years. Out of 100 ACS patients, 62 were STEMI, 20 were NSTEMI, and 18 were unstable angina. The prevalence of ACS was higher in males than females. Hypertension is the most common risk factor of ACS (41\%) followed by diabetes mellitus (33\%). We found that high levels of TC (more than $200 \mathrm{mg} / \mathrm{dl}$ ) were found in $31 \%$ patients [mean \pm SD $(167.79 \mathrm{mg} / \mathrm{dl} \pm 45.28)]$. High levels of LDL (more than $130 \mathrm{mg} / \mathrm{dl}$ ) were found in $23 \%$ patients [mean \pm SD $(97.47 \mathrm{mg} / \mathrm{dl} \pm$ 38.24)]. Low levels of HDL (less than $40 \mathrm{mg} / \mathrm{dl}$ ) were found in $52 \%$ patients [mean $\pm \mathrm{SD}(40.69 \mathrm{mg} / \mathrm{dl} \pm 11.84)]$. High levels of TG (more than $150 \mathrm{mg} / \mathrm{dl}$ ) were found in $37 \%$ patients [mean \pm SD $(145.28 \mathrm{mg} / \mathrm{dl} \pm 65.78)]$.

\section{CONCLUSIONS}

Dyslipidemia is one of the major risk factors which is widely prevalent in patients with ACS and is more prevalent in males than in females. We recommend paying more attention to serum lipids and other modifiable risk factors for prevention of ACS

\section{KEY WORDS}

Acute Coronary Syndrome, Dyslipidemia, MICU, Tertiary Care Hospital
Corresponding Author:

Dr. Aparna Patange,

Krishna Institute if Medical Sciences,

NH4, Pune-Bangalore Highway,

Dist-Satara, Agasivnagar, Malkapur,

Maharashtra-415539

E-mail: hetal.mankodia14@gmail.com

DOI: $10.14260 /$ jemds/2020/117

Financial or Other Competing Interests: None.

How to Cite This Article:

Patange A, Immadisetty S, Vora $H$, et al. Lipid levels in acute coronary syndromes admitted in medical intensive care unit in a tertiary care hospital. J. Evolution Med. Dent. Sci. 2020;9(08):520-523, DOI: 10.14260/jemds/2020/117

Submission 14-04-2018,

Peer Review 25-01-2020,

Acceptance 04-02-2020,

Published 24-02-2020. 


\section{BACKGROUND}

Acute coronary syndrome (ACS) remains the leading cause of mortality in the world, especially in the developing countries, where the incidence has doubled in last 3 years. This change in health risk is particularly evident in newer generation, which may be due to changes in dietary habits, physical activities along with genetic, metabolic, and environmental factors. Although it is a global issue, Indian population has very high incidence of ACS even at low levels of many of these risk factors by comparison with Western standards.[1] Initially, it was considered as the problem of modern Indian society but gradually its incidence is increasing also in the rural part of the country. There are no detailed reports, but mortality and morbidity surveys in India indicate that there is significant variation in the prevalence of cardiovascular diseases, which may be due to substantial regional variation in lifestyle and dietary habits in the country. ${ }^{[2]}$ Hypertension, diabetes mellitus and Cigarette smoking have been reported to be risk factors of $\mathrm{CAD}$ and stroke through many studies, ${ }^{[3,4,5]}$ respectively. The risk of CAD was about 4 and 3 times higher in male and female smokers than non-smokers respectively.[6]

Elevated levels of total- and low density lipoprotein cholesterol (TC and LDL-C), elevated levels of triglyceriges (TG) and low levels of high density lipoprotein cholesterol (HDL-C) are important risk factors for CAD.[7] LDL-C is considered as 'bad cholesterol' since too high level of this cholesterol is associated with an increased risk of coronary artery disease and stroke. ACS is classified as unstable angina (UA) or non-ST elevation myocardial infarction (NSTEMI) and STEMI depending on occurrence of ST segment elevation on electrocardiogram. This study focused on dyslipidaemia as a risk factor of acute coronary syndrome (ACS). The aim of the study was to determine the prevalence and pattern of dyslipidaemia in subjects with acute coronary syndrome, its relation to age, gender and other modifiable risk factors.

\section{METHODS}

Total 100 cases were studied in a Krishna Institutes of Medical Sciences, Karad. The study was carried out in a 12 months period from $1^{\text {st }}$ August 2015 to 31 July 2016. Study Design was Prospective Observational study. All adult age $>18$ years admitted for acute coronary syndrome were eligible for this study. The ACS group was studied as STEMI, NSTEMI, and Unstable Angina. ACS was identified on the basis of typical history of angina, ECG changes with or without elevated cardiac enzymes. Patients with history or presence of any of following were excluded from this study. a)Chronic kidney disease (creatinine $\geq 2 \mathrm{mg} / \mathrm{dL}$ ), b) Valvular Heart Diseases, c) Congenital Heart Diseases, d) Lipid lowering agent.

\section{Sample Size Estimation}

According to a study conducted by A Esteghamati et al,[8] the prevalence of hypercholesterolemia in patients with acute coronary syndrome is $41.2 \%$. So, $p=41.2 \%$. Using formula for sample size (n) calculation,

$$
n=\frac{4 \times p \times q}{e^{2}}
$$

Where, $\mathrm{p}=41.2 \%=0.412, \mathrm{q}=1-\mathrm{p}=0.588$

Taking e, absolute error of $10 \%, \mathrm{e}=0.1$

So, $\mathrm{n}=4 \times 0.412 \times 0.588$

$0.1 \times 0.1$

$\mathrm{n}=96.90 \approx 97$

Minimum sample size required to carry out this study is 97 , rounding it up to 100 .

So, Sample size $=\mathrm{n}=100$.

All Patients underwent thorough history included time of onset of typical chest pain, nature of pain, increasing with exertion and associated symptoms like excessive sweating, breathlessness. A thorough clinical examination was carried out in each case with special reference to pulse, blood pressure, cardiovascular and respiratory examination for the presence of murmur, crepitations, S3 gallop. During hospitalization, complete blood count, urine, fasting \& post prandial blood glucose, lipid profile, blood urea, serum creatinine, chest x-ray, ECG, CPK MB, Troponin-I and 2D echo were done. Sample taking - $5 \mathrm{ml}$ blood were withdrawn from each case after overnight fasting of 12 hours then centrifuged at $3000 \mathrm{rpm}$ for 10 minutes.

\section{Statistical Analysis}

Data Collected was entered in Microsoft Excel. Data is represented in frequencies and percentages, charts and graphs. Mean and standard deviation of quantitative variables is shown. Appropriate statistical tests will be applied using SPSS software version 21 for analysis. Chi square test was used for association and student's t-test was used for comparison wherever applicable.

\begin{tabular}{|c|c|}
\hline \multicolumn{2}{|c|}{ RESUL T S } \\
\hline \multicolumn{2}{|c|}{} \\
\hline No. of Cases & $\mathbf{1 0 0}$ \\
\hline Male & 68 \\
\hline Female & 32 \\
\hline Mean Age of the participants (Years) & 58.58 \\
\hline Range for Age (Years) & $28-85$ \\
\hline Table 1. Demographic Data of ACS \\
\hline
\end{tabular}

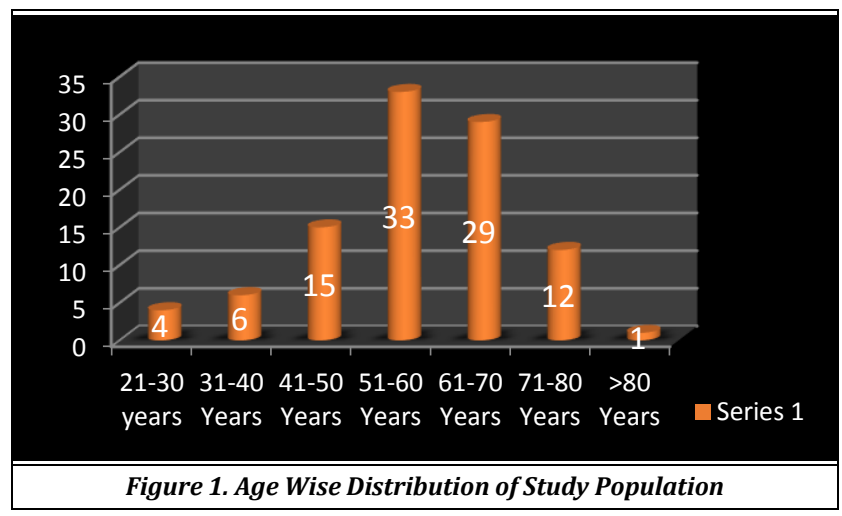

Table 1 shows that, the total of 100 patients were examined in the study, of which $68 \%$ were male and $32 \%$ were females. Figure 1 shows that, maximum of patients 33 were in the age group 51-60 years followed by 29 patients in 
the age group 61-70 years. 15 and 12 patients were in the age group of 41-50 and 71-80 years respectively. Minimum 1 patient was in the age group of $>80$ years. Table 2 shows that, out of 100 ACS patients, 62 were STEMI, 20 were NSTEMI, and 15 were unstable angina. The prevalence of ACS was higher in male gender than females, but there was no any association between the sex of the participants and type of coronary artery disease $(p=0.34)$. Table 3 shows that, Low level of HDL was the most common, followed by high TG, high TC then high level of LDL. Figure 2 Shows that, hypertension is the most common risk factor of ACS (41\%) followed by diabetes mellitus (33\%). Significant association was seen between the disease distribution in our study and age groups $(p=0.037)$. With higher age groups patients having more percentage of STEMI as compared to younger ages.

\begin{tabular}{|c|c|c|c|}
\hline & Male & Female & Total \\
\hline STEMI & 45 & 17 & 62 \\
\hline NSTEMI & 11 & 9 & 20 \\
\hline Unstable Angina & 12 & 6 & 18 \\
\hline Total & $\mathbf{6 8}$ & $\mathbf{3 2}$ & $\mathbf{1 0 0}$ \\
\hline \multicolumn{4}{|c|}{$\mathrm{X}^{2}=2.17, \mathrm{p}=0.34$} \\
\hline Table 2. Disease Distribution in the Study According to Gender \\
\hline
\end{tabular}

\begin{tabular}{|c|c|c|c|}
\hline Type of Lipid & \% & (Mean \pm SD) & p-value \\
\hline Total cholesterol [TC] $(>200 \mathrm{mg} / \mathrm{dl})$ & $31 \%$ & $167.79 \pm 45.28$ & $<0.001$ \\
\hline Triglycerides [TG] $(>150 \mathrm{mg} / \mathrm{dl})$ & $37 \%$ & $145.28 \pm 65.78$ & 0.47 \\
\hline Low density lipoprotein $[\mathrm{LDL}](>130 \mathrm{mg} / \mathrm{dl})$ & $23 \%$ & $97.47 \pm 38.24$ & 0.0016 \\
\hline High density lipoprotein [HDL] $(<40 \mathrm{mg} / \mathrm{dl})$ & $52 \%$ & $40.69 \pm 11.84$ & $<0.001$ \\
\hline
\end{tabular}

Table 3. Prevalence and Pattern of Dyslipidemia in Patients with ACS

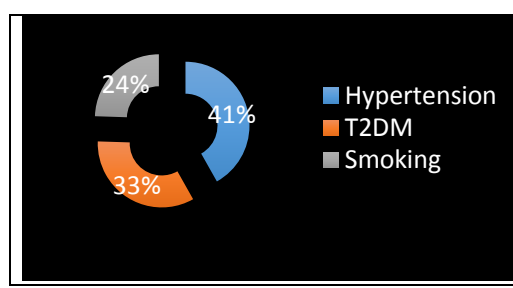

Figure 2. Prevalence of Risk Factors in the Study

\begin{tabular}{|c|c|c|c|c|}
\hline Disease \& Age Groups & $\mathbf{< 4 0}$ & $\mathbf{4 0}-\mathbf{6 0}$ & $\mathbf{7 6 0}$ & Total \\
\hline STEMI & 2 & 52 & 8 & 62 \\
\hline NSTEMI & 3 & 14 & 3 & 20 \\
\hline Unstable angina & 5 & 11 & 2 & 18 \\
\hline Total & $\mathbf{1 0}$ & $\mathbf{7 7}$ & $\mathbf{1 3}$ & $\mathbf{1 0 0}$ \\
\hline $\mathrm{X}^{2}=10.24, \mathrm{p}=0.037$ & Table 4. Disease Distribution According to Age Groups \\
\hline
\end{tabular}

\begin{tabular}{|c|c|c|c|}
\hline HTN & Present & Absent & Total \\
\hline STEMI & 30 & 32 & 62 \\
\hline NSTEMI & 9 & 11 & 20 \\
\hline Unstable angina & 2 & 16 & 18 \\
\hline Total & $\mathbf{4 1}$ & $\mathbf{5 9}$ & $\mathbf{1 0 0}$ \\
\hline $\mathrm{X}^{2}=8.18, \mathrm{p}=0.017$ & \multicolumn{3}{|l}{} \\
\hline \multicolumn{4}{|l}{ Table 5. Disease Distribution and Hypertension } \\
\hline
\end{tabular}

\begin{tabular}{|c|c|c|c|}
\hline T2DM & Present & Absent & Total \\
\hline STEMI & 29 & 33 & 62 \\
\hline NSTEMI & 3 & 17 & 20 \\
\hline Unstable Angina & 1 & 17 & 18 \\
\hline Total & $\mathbf{3 3}$ & $\mathbf{6 7}$ & $\mathbf{1 0 0}$ \\
\hline $\mathrm{X}^{2}=14.38, \mathrm{p}<0.001$ & Table 6. Disease distribution and Type 2 DM \\
\hline \multicolumn{4}{|l}{} \\
\hline
\end{tabular}

\begin{tabular}{|c|c|c|c|}
\hline Smoking & Present & Absent & Total \\
\hline STEMI & 15 & 47 & 62 \\
\hline NSTEMI & 7 & 13 & 20 \\
\hline Unstable angina & 2 & 16 & 18 \\
\hline Total & $\mathbf{2 4}$ & $\mathbf{7 6}$ & $\mathbf{1 0 0}$ \\
\hline $\mathrm{X}^{2}=2.97, \mathrm{p}=0.23$ & \multicolumn{3}{|c|}{} \\
\hline \multicolumn{3}{|c|}{ Table 7. Disease Distribution and Smoking } \\
\hline
\end{tabular}

There was significant association between the disease distribution and presence of Hypertension ( $p=0.017)$. With $30 \%$ cases having STEMI from total $41 \%$ cases of hypertension. Significant association was seen between the type 2 Diabetes Mellitus and disease distribution. There was no any association between the distribution of disease in study population and smoking $(\mathrm{p}=0.23)$.

\section{DISCUSSION}

CAD is a complex and multifactorial process that manifests as stable angina, unstable angina or myocardial infarction. The atherosclerotic process underlies each of these pathologies. Indeed, clinical symptomatology in CAD is frequently triggered by a thrombus formation on an eroded or ruptured atherosclerotic, lipid-rich plaque characterized by a thin fibrous cap. ${ }^{[7]}$ CAD is the leading cause of death in men and women. [9] Dyslipidemia preponderated among the nine major risk factors (smoking, diabetes, hypertension, visceral obesity, psychosocial stress, sedentary life, low fruit and vegetable consumption and alcohol consumption), and alone accounted for more than $50 \%$ of population attributable risk.[10] Regardless of declines in developed countries, both CAD mortality and the prevalence of CAD risk factors continue to rise rapidly in developing countries.[11] Hypertension is a clear risk factor of atherosclerotic CAD. [12] The risk of CAD has been reported to be 2-6 times higher in diabetics than in nondiabetics.[3] Cigarette smoking has been reported to be a risk factor of CAD and stroke through many studies.[4] The risk of CAD was about 4 and 3 times higher in male and female smokers than non-smokers respectively.[5] Dyslipidemia, manifested by elevated levels of total- and low density lipoprotein cholesterol (TC, LDL-C), low levels of high density lipoprotein cholesterol (HDL-C) and high levels of triglycerides (TG), is an important risk factor for CAD.

Our study revealed that hypertension is the most common risk factor of ACS (41\%) followed by diabetes mellitus (33\%). Cigarette smoking came at the last (23\%). Our results agreed with Sandhu et al., Lahoz et al., and Cooke et al., (2006).[13,14,15] And we found significant association between the hypertension, T2DM and disease distribution while there was no any association between smoking. Saito et al.,[16] found that the prevalence of hypertension was $45.8 \%$, diabetes mellitus was $15.8 \%$ while cigarette smoking was $16.7 \%$ which differs regarding the prevalence from our study. According to Saito et al, hypertension was the commonest risk factor of acute coronary syndrome followed by cigarette smoking, diabetes mellitus came at the last. In our study smoking, as a risk factor for ACS, came after hypertension and diabetes mellitus, probably, because all our female patients were non-smoker. Our study revealed that myocardial infarction (MI) was found in $82 \%$ patients, out of $82 \%$ patients $62 \%$ were STEMI and $20 \%$ were NSTEMI while unstable angina (UA) was found in $18 \%$ patients. The prevalence of ACS was higher in male gender than females 68 $\%$ vs $32 \%$ respectively. This can be explained by our finding that hypertension, T2DM and smoking were more prevalent in males than in females. Smokers were only males. 
Regarding prevalence and pattern of dyslipidaemia in our study, we found that high levels of TC (more than $200 \mathrm{mg} / \mathrm{dl}$ ) were found in $31 \%$ patients [mean \pm SD $(167.79 \mathrm{mg} / \mathrm{dl} \pm$ 45.28)]. High levels of LDL (more than $130 \mathrm{mg} / \mathrm{dl}$ ) were found in $23 \%$ patients [mean \pm SD $(97.47 \mathrm{mg} / \mathrm{dl} \pm 38.24)$ ] Low levels of HDL (less than $40 \mathrm{mg} / \mathrm{dl}$ ) were found in $52 \%$ patients [mean $\pm \mathrm{SD}(40.69 \mathrm{mg} / \mathrm{dl} \pm 11.84)]$. High levels of TG (more than $150 \mathrm{mg} / \mathrm{dl}$ ) were found in $37 \%$ patients [mean \pm SD (145.28 mg/dl \pm 65.78$)]$. Our results were in agreement with that of Kamariya et al.,[17] and Yadav and Bhagwat who reported increased TC, TG, LDL and decreased HDL levels in patients with ACS.

\section{CONCLUSIONS}

Hypertension was the most common risk factor for ACS followed by diabetes mellitus. Smoking was the last risk factor. Hypertension and smoking were more prevalent in males than in females. Regarding dyslipidaemia, we found that dyslipidaemia was prevalent in ACS patients. Low level of HDL was the most common, followed by high TG, high TC then high level of LDL. Based on these results, we can recommend paying more attention to serum lipids for prevention of acute coronary syndrome, periodic check of fasting lipid profile and educating people about dyslipidaemia, its hazards, and how to avoid.

\section{REFERENCES}

[1] Walia R, Bhansali A, Ravikiran M, et al. High prevalence of cardiovascular risk factors in Asian Indians: a community survey - Chandigarh Urban Diabetes Study (CUDS). Indian J Med Res 2014;139(2):252-9.

[2] Gupta R, Guptha S, Sharma KK, et al. Regional variations in cardiovascular risk factors in India: India Heart Watch. World J Cardiol 2012;4(4):112-20.

[3] Haffner SM, Lehto S, Rönemaa T, et al. Mortality from coronary heart disease in subjects with type 2 diabetes and in non-diabetic subjects with and without prior myocardial infarction. N Engl J Med 1998;339(4):229-34.

[4] Wolf PA, D'Agostino RB, Kannel WB, et al. Cigarette smoking as a risk factor for stroke: the Framingham Study. JAMA 1988;259(7):1025-9.

[5] Baba S, Iso H, Mannami T, et al. Cigarette smoking and risk of coronary heart disease incidence among middleaged Japanese men and women, the JPHC Study Cohort. Eur J Cardiovasc Prev Rehabil 2006;13(2):207-13.
[6] Yadav AS, Bhagwat VR. Lipid profile pattern in Anginal syndrome patients from Marathwada region of Maharashtra State. Journal of Medical Education \& Research 2012;2(2):12-5.

[7] Libby P. The molecular mechanisms of the thrombotic complications of atherosclerosis. J Intern Med 2008;263(5):517-27.

[8] Esteghamati A, Abbasi M, Nakhjavani M, et al. Prevalence of diabetes and other cardiovascular risk factors in an Iranian population with acute coronary syndrome. Cardiovascular Diabetology 2006;5(1):15-8.

[9] Thom T, Haase N, Rosamond W, et al. Heart Disease and Stroke. Statistics - 2006 Update. A report from the American Heart Association Statistics Committee and Stroke Statistics Subcommittee. Circulation 2006;113(6):e85-151.

[10] Yusuf S, Hawken S, Ounpuu S, et al. Effect of potentially modifiable risk factors associated with myocardial infarction in 52 countries (the INTERHEART study): case-control study. Lancet 2004;364(9438):937-52.

[11] Okrainec K, Banerjee DK, Eisenberg MJ. Coronary artery disease in the developing world. Am Heart J 2004;148(1):7-15.

[12] Kannel WB. Fifty years of Framingham Study contributions to understanding hypertension. J Hum Hypertens 2000;14(2):83-90.

[13] Sandhu KS, Singh A, Nadar SK. Management of elderly patients with troponin positive chest pain in a District General Hospital. Cardiol J 2012;19(4):395-401.

[14] Lahoz C, Mostaza JM, Tranche S, et al. Atherogenic dyslipidemia in patients with established coronary artery disease. Nutrition, Metabolism \& Cardiovascular Diseases 2012;22(2):103-8.

[15] Cooke CE, Hammerash WJ Jr. Retrospective review of sex differences in the management of dyslipidemia in coronary heart disease: an analysis of patient data from a Maryland-based health maintenance organization. Clin Ther 2006;28(4):591-9.

[16] Saito Y, Kita T, Mabuchi H, et al. Obesity as a risk factor for coronary events in Japanese patients with hypercholesterolemia on low-dose simvastatin therapy. J Atheroscler Thromb 2010;17(3):270-7.

[17] Kamariya CP, Gorasia JH, Vachhani U, et al. Evaluation of serum lipoprotein (a) in young patients with myocardial infarction. International Journal of Medicine and Public Health 2014;4(1):107-9. 